\title{
X. Ueber die Schavefelblumen;
} von Dr. J. Fritzsche.

(Nitgetheilt vom Verfasser aus den Berichten der Petersimeswe Academic.)

Bei der unikroskopischen Untersuchung der im Handel vorkommenden Schwefelblumen fand ich, dafs die Annahme, die Schwefelblumen bestehen aus sehr feinen Krystallen, unrichtig sey, und dals dieselben vielmehr ein Haufwerk kleiner, mannigfach at ciuander gereiltex Kugeln darstellen, deren Durchmesser bei den von mir untersuchten ungefähr zwischen $3^{\frac{i}{\sigma}}$ bis $\frac{1}{\delta} \sigma$ einer Linie variirte. Sie sind bei eincr 200 maligen Linearvergröfserung, deren ich mich im Verlaufe dieser Untersuchungen fortwäbrend bediente, selbst in Flüssigkeiten liegend betrachtet, fast ganz undurchsichtig, ihre Obertläche ist glatt; sie geben beim Zerdrücken unregelıärsige Bruchstücke, und es lärst sich also durch dic Beobachtung keine krystallinische Structur an ihuen nachweisen, obgleich wir sie ilnen der Theorie nach dennoch zuschreiben müssen. Un zu crfahren, welchem Umstande sie ibre Kugelgestalt verdanken, destillirte ich Schwefel aus einer kleinen Retorte, liefs den, in Aufange der Destillation sich bildenden Strom von Schwefelblumen auf kleine Glasplatten fallen, und erbiclt so, wenn ich den Strom nur sebr kurze Zeit auf cine Stelle fallen liefs, in kleineren oder grofseren Abständen von einander liegende Kugeln, deren Durchmesser rơ bis tơ einer Linie ungefähr betrug. Sie sind, so frisch bereitet, durchsichtig, und befinden sich in dem bekannten zähen Zustande des Schwefels, was sich mit vicler Leichtigkeit nachweisen läfst, wenn man mit dem Finger über sie hinfährt, wodurch sie theils zusammengeballt, theils in 
lange Fäden ausgezogen werden. Läfst man solche, mit frisch gebildeten Schwefelblumen bestreute Glasplatten an der Luft liegen, ohne sie zu berühren oder überhaupt zu erschuttern, so bleiben die Kugeln mehrere Tage lang unverändert, und da in den Kamimern, wo man in Grofsen Schwefelblumen darstellt, nicht nur diese Bedingungen vollkommen erfullt sind, sondern auch noch ein Mangel an Licht stattfindet, so sind diefs wabrscheinlich die Gründe, weshalb die Schwefelblumen bei ihrem allıäligen Erhärten ihre runde Form und glatte Oberfläche beibehalten. Diefs findet nămlich nicht statt, wenn die Glasplatten, worauf die zăhen Kugeln sich befinden, èrschüttert und dem Lichte ausgesetzt werden; es geht dann eine fortscbreitende Veranderung vor sich, und man erhält, nach kürzerer oder lăngerer Dauer des Liegens, verschiedene Producte. Die ersten Folgen der Erscbütterung sind ein Zusammenfliefsen nahe liegender Kugeln ohne weitere Verănderung; selbst nach einigen Tagen sind die Kugeln noch flüssig genug, um diese Erscheipung zu zeigen, und der, durch ein starkes Ausathmen während der Beobachtung durch das Mikroskop, hervorgebrachte Luftstrom reicht hin sie hervorzurufen. Die crste Veränderung ihrer Structur beginnt nun nach einer oder einigen Stunden, oder selbst in noch kürzerer Zeit, und bestebt in einem Undurchsichtigwerden, welches gewöhnlich mit dem Verluste der glatten Oberflache und der Kugelgestalt zugleich eintritt, und von dem ersten Schritte zur Annahme einer krystallinischen Structur herrübrt. Die Kugeln breiten sich nämlich auf der Glasplatte aus, und es entstehen daraus mebr oder weniger regelmälsige Halbkugeln, aus deren Oberfläche Enden von Krystallen als kleine Spitzen hervorragen. Allmälig nehmen diese Spitzen sowohl an Unfang als an Lange zu, und bilden nach einigen Tagen einen durcbsichtigen Ring von kleinen Krystallen um den dunkeln, durch die krystallinische Structur der Oberflïche mar- 


\section{5}

morirt erscheinenden Kern, welcher noch. längere Zeit in seinem zäben Zustaude zu verharren sçheint; vicht selten auch siud dann aus ibnen feine, prismatische, blattartige Krystalle herausgewachsen, deren Liinge oft das Doppelte des Durchmessers des Schwefelkornes beträgt. Nach 5 bis 6 Tagen sind schon viele dicser Köruer ganz durchsichtig geworden, und bilden dann Gruppen von Krystallen; aus anderen sind einzelne, vollkommen ausgebildete Krystalle entstanden, und da gewöhnlich auch noch ganz unveränderte zähe Kugeln vorhanden sind, so bietet eine, anfangs mit kleinen Kugeln gleichförmig besäet gewesene Glasplatte: vun alle Slufen der crfolgten Veränderungen dar.

Die : Bildung der cinzelnen Krystalle, deren Form unverkennbar das Rhombenoctaëder des Schwefels ist, kaun man schon nach einigen Stunden dadurch hervorrufen, dafs man mit einer Nadelspitze Striche durch dic auf einer Glasplatte befindlichen frisch gebildeten Kugeln ziebt; es bleibt dabci gewöhnlich eine sehır dünnc Schicht Schwefel auf der Flache des Glases kleben, und die so gebildeten Strafsen erscheinen nach kurzer Zeit ınit kleinen Krystalleu besïet, deren Forn unan, trotz dem, das der Iurchmesser ihrer Hauptaxe oft nur zivo einer Linie beträgt, mit völliger Bestiınmtheit erkennen kann. Grúfsere einzelne Krystalle bilden sich, wie es scheint, ununillelbar durch die alluälige Linwirkung des Lichts aus Kugeln, welche durch Zusammenfliefsen mehrerer kleiver gebildet worden sind; ich fand sie in allen Grölsen bis zu $\frac{1}{2}$ 's Linie Durchmesser ihrer Hauptaxe.

Weit eiufacher erscheint der Verlauf der Veränderungen, und weit schueller ist er vollendet, wenu man die mit frischen Schwefelblunen bestreuten Glasplatten unit Oel benelzt. Die Kugeln behalten dann ihre Form und Durchsichtigkeit, werden aber alhmälig kleiner, und es bilden sich dafür an einzelnen Stellen grofse Krystalle, von denen ich einen in weuigen Stunden bis zu 


\section{6}

$\frac{1}{6}$ Linie Durchmesser der Hauptaxe angewachsen tand. Viele derselben baben eine Menge secundärer Flăchen (Abstumpfung und Zuspitzung der Eudecken etc.), andere sind dendritenförmig an einander gereiht, und noch andere bilden dünne Blätter oft bis über $\frac{1}{2}$ Linie Länge. Läfst man die frischen Schwefelblumen auf Glasplatten fallen, welche vorher mit Oel bestrichen waren, so gebt die Umwandlung der Kugeln in grofse Krystalle noch schneller und schöner vor sich, indem dann wahrscheinlich die Adhäsion des Schwefels an Glase nicht hindernd einwirken kann. Unstreitig spielt bei dieser merkwürdigen Umwandlung das Auflösungsvermögen des Oeles für den Schwefel eine wichtige Rolle; unbegreitlich bleibt es aber, warum das Oel gleichsam nur den Verınittler zur Krystallbildung spielt, und den eben aufgelösten Schwefel sogleich wieder absetzt.

Läfst man zähen Schwefel als Fäden in Oel fallen, so bleibt dieses so lange ohne Einwirkung, als jene ihren zithen Zustand behalten; sobald sie aber anfangen undurchsichtig zu werden, so bedeckt sich ihre Oberfläche glcichzeitig mit kleinen Krystallen, welche bei geringer Berührung sich ablösen und als vollkommen ausgebildete Individuen sich darstellen. Giefst man auf geschmolzenen Schwefel Oel und lälst ihn nun erkalten, so bilden sich in dem Ocle ziemlich grofse Krystalle, die man sebr bequem mit blofsem Auge erkennen kann; siè entsteh en aber nicht unmittelbar nach dem Erkalten, sondern erst nach einigen Stunden, und wahrscheinlich waren auch in diesem Falle keinesweges alle: Krystalle auf einnal in dem Oele aufgelost gewesen, sondern bildeten sich auf dieselbe Art, wie jene aus den Kugeln. Hatte das Oel, welches man zu diesen Versuche anwendete, vorher schon mit Schwefel in Bcrührung gestanden, so erfolgte' die Bildung der Krystalle sehr viel schneller; es bildete sich in diesem Falle zuerst eine Menge langer, blattartiger Krystalle in dem Oele,' wel- 
che jedoch nach einiger Zeit entweder sich in eine zusammenhăngende Masse kleiner, rhombenoctaëdrischer Krystalle mit Beibebaltung ibrer Form umwandelten, oder auch ganz verscluranden, indem sich an anderen Stellen eine Menge kleiner Khombenoctaëder bildeten. Es scheint daraus einerseits hervorzugehen, dafs die blatlartigen $\mathrm{Kry}$ stalle der zweiten prismatischen Form des Schwefels angebörten, und andererseits scheinen diese Versuche zu beweisen, dafs das Oel die oben beschriebene Einwirkung auf den Schwefel nur dann äufsert, wenn der Schwefel krystallinische Structur anzunehmen im Begriff steht oder eben angenommen bat.

Legt man sehr feine, eben gebildete, durch Schmelzen erhaltene Schwefelkrystalle in Oel, so wird die Einwirkung desselben erst nach 10 bis 14 Tagen bemerkbar; es wandeln sich aber hierbei nur die Krystalle selbst in aneinandergereihte Krystalle der rhombenoctaëdrischen Form um, und man siebt keine Krystalle um sie herum in dem Oele entsteben. Waren die Krystalle durch Liegen an der Luft schon undurchsichtig geworden, ehe man sie in Oel legt, so bemerkt man auch nach langem Liegen keine andere Einwirkung, als dafs sich die Krystalle gleichsam mit einem Netze ungeben, als ob das Oel den einen Theil des Krystalles aufgelöst und ausgefressen, den anderu dagegen unangetastet gelassen habe; die Theilchen, ans welchen dieses Nelz besteht, sind aber 80 klein, dafs es unmöglich ist zu bestimmen, ob sie Krystalle sind oder vicht. An käuflichèn Schwefelblumen sah ich, aucb nach langem Liegen in Oel, keine Veränderung.

Um zu untersuchen, in welcher Form der Schwefel bei seiner Ausscheidung auf nassem $W$ ege sich zeigl, wählte ich dic Zersetzung des untersclweflichtsauren Natrons durch Säure, und fand, dafs der Schwefel auch hierbei in seinem zähien Żustande ausgeschieden wird. Er bildet, nach Verhältwifs der Concentration der Lösungen; grölsere oder kleinere Kugeln, welche unter Was. 


\section{8}

ser lăngere Zeit ihren zähen Zustand beibehalten; an der Luft and mit Oel aber ahnliche Erscheinungen geben wie die frischen Schwefelbluinen. Den bei anderen Zersetzungen :abgeschicdenen Schirefel habe ich nieht untersucht, weil sie ja fast nur bei gleichxeitigem. Varhandenseyn ron : Schwefelwasserstoff erfolgen, und dann ein Wasserstoffgehalt Ursache eines weichen Aggregatzustanles seyn konnte').

XI:- Untersuchung eines, nach einern Anfall von Magenkrampf gelisssieners Harns; onn Leopold Grnelin in Heillelherg.

Der Harn war klar, in Masse braun wic Bier, in dinnen Schichten gelb.

Mit viel Salzsüure lieferte er ein klares, braunes Gemisch, mit viel Salpetersäure; in klares rothes Gemisch, ohue dafs : der rolben Firbung cine grïne und violette vorangegabgen wäre.

Weuig Salzsüure veranlifste Trubung und:braunen Niederschlag. Dieser lüste sich in wäfsrigem Kali zu einer dunkelbraunen Fliissigkcit, welche mit wenig Salpetersäure. einen violetten Niederschlag, mit melir Salpetersäure eine. schün rothe Lüsung gab (ebenfalls ohne dals eine grüue Färbung vorausgegangen wäre). Auch liefs. jener brauue Niederschlag, mit Salpetersäure abgedampft, einen schönen rothen Fleck vou Purpursäure.

Wenig. Salpetersïure verhiclt sich gegen den Harn wie wenig Salzsäure, nur war die rothe Färbuug des in Kali gelüsten Niederscblages durch Salpetersüure weniger lebbaft:

Der Hatu, 2t Stunden sich selbst tiberlassen, gab ein rosenrothes Sediment, blieb aber noch braun, und gab eit wenig Satzsäure déuselben Niederschlag. wic oben.

1) Vergl. Frankenliein, Aonal. Bd. XXXIX S.376.

p. 